\section{В.С. Баранов}

НИИ акушерства и гинскологии им. Д.О. Отта РАМН, Санкт-ІІетербург

\author{
ЭКОЛОГИЧЕСКАЯ ГЕНЕТИКА, \\ РЕПРОДУКТИВНОЕ ЗДОРОВЬЕ \\ И ПРЕДИКТИВНАЯ МЕДИЦИНА
}

\section{- Экологчческой генеткке человека прннадлежит важная роль в сохранения репродуктивного зиоровья. В рсшенни этой сложной пробллемы решаюцее ме- сто отводктся охране релродуктивной фучкщии женщины-матери, повреждаю- щсе действне внешней среды на гаметы которой возможнно на протякенни не-} скольких поколений. Эффективная профнлактнка наследственньх болезней, врожденных пороков н доснмптомапнческая диагностика нанболее частьх забюлеваний может быть достнгнута с помошью преднктивной медицины, методическую основу которой составляет тестирование полиморфизмов гепов «предрасположенности» и, прежце всего, генов системы детоксикащия. Разработанғые в настоямее время методы ДНК-ана.таза позволяют уже сегодня сделать такне исследования массовыми, то есть перевести тестиропание на уровень популяннонного скрининга. Требуются, однако, дальнейшие исследовання ілия оценки предиктивной ценности генетических тестов. Серьезћым препятствием к их широкому внсдрсния явается отсутствне соответствуюш(ей юридической и правовой базы, отсутствне готовности современной медиципы $к$ переориентации в сторону охраны здоровья здорового человека. Такие исследования, а также внедрение в работу родовспомогательньх учреждений «гене тической карты репродуктинного здоровья", будут способствовать сохранению репродуктивного здоровья населения Россин и повысят эффектнвность профилактикн наследственных и врождснньх заболеваний.

- Kлnочевые слова: экологическая генетика; репродуктинное здоровье; предиктивная медицина; генетическое тестирование; гены предрасположенHости

\section{Введение}

На фоне существенного падения рождаемости и нгизбежно надвигающсгося демографичсского дефолта в нашей стране особенно большое значение приобретают рождение полноценного здорового потомства и сохранение репродуктинного здоровья населения России [1, 2]. Последнес, кстати, нередко рассматривается как наиболее чувствительный показатель повреждающего действия окружаюшей среды на организм человека [3]. $\mathrm{K}$ сожалению, сушествующие статистические данные свидетельствуют о весьма тревожном состоянии репродуктивного здоровья населсния России в настоящее время и о наличии значительного груза пеблагоприятных мутаций у жителей нашей страны.

Согласно официальной статистике в Российской Федерации на қаждую тысячу новорожденных приходится 50 детей с врожденными и наследственными заболеваниями. При этом перинатальная патология регистрируется у $39 \%$ детей в неонатальном периоде и остается основной причиной мјаденческой смертности (13,3 на 1000$)$ [4]. Если к этому добавить, что полти 15\% всех супружеских бесплодны, а $20 \%$ регистрируемых беремснностей заканчивается спонтанными абортами, то картина репродуктивного здоровья населения России выслядит удручающе.

\section{Экология, геном и репродуктивное здоровье}

Экологицеская генетика неловека - научная дисципьина, изучаюшая влияние экологических факторов или среды обитания на наследственность и здоровье ченовека [5]. Репродуктивное здоровье человека, равно как и развитие всего организма, его систем и органов формируется как результат постоянного взаимодействия генома челонека, то есть набора всех его генов с постоянно меняюпимися факторами окружаюшей среды. При этом нарушения репродукции, включая бесплодие, рождение детей с врожденными и наследственными пороками, а также заболевания постнатального периода могуг быть как следствием уже существуюцих ошибок в геноме (мутации), так и результатом повреждающего действия на организм различных неблаголриятных экологических факторов на разных стадиях онтогенеза [6].

В настояпее время хорошо известно, что наряду с мозгом, эндокринной и иммунной системами полнопенное развитие и функции репродуктивной системы человека требует гармоничной и эффективной работы многих тысяч генов, нормальная активность которых возможна только лри наличии благоприятных условий внешней среды. Зачатие, внутриутробное развитие плода, беременность и роды, являются теми событиями в онтогенезе человека, когда естественным путем испытываются качества ще только геномов родителей и плода, но автоматически тестируются условия внешней среды, способствуюшие или наоборот, прелятствуюшие этим процессам.

Важно обратить внимание на особое, центральное место женшины в процессах репродукции. Дело в том, что в отличие от 
мужских гамет, возникаюпих в лроцессе сперматогенеза и постоянно обновляюциихся на цротяжеции всей жизни мужчины, женские гаметы, яйцекіетки, закладываются еще во внутриугробном периоде, когда не только возникают первичные половые клетки, но и происходят кардинальные события в оогенезе, связанные с процессами мейоза. Уже с 3-го месяша беременности ооциты, находящисся в зачатках первичных гонад, прекрашают делиться, окружаются фолтикулярными клетками и вступают в профазу мейоза, которая продолжается почти до конца беременности [7]. При рождении они находятся В состоянии покоя (диктиотены) и возобновляют мейоз только в гериод полового созревания. Завершение мейоза происходит после оллодотворения, причем качество и эффективность начальғых стадий развития зародыша целиком определяется особенностями генома яйцеклетки на предшествуюших стадиях ее развития

Мы столь подробно останавливаемся на этих особенностях проэмбрионального периода, чтобы подчеркнуть тот удивительный, но, к сожалению, часто игнорируемьй факт, что каждая яйцектетка - ее становленис, развитие- является важным связующим звеном трех посједовательных поколений:

- бабушки, в утробе которой развивается плод женского пола и, соответственно, в организме которого происходят важные начальные этапы мейоза;

- матери, у которой созревают и овулируют яйцеклетки;

- и наконец, нового организма, возникающий после опјодотворепия такой яйцеклетки [8].

Таким образом, в отличие от мужчин, где весь процесс созревания сперматозоидов, нключая мейоз длится чуть болсе 2-х месяцев, а селекция генетически нелолноценных гамет весьма эффективна, женские половые кіетки чувствительны к внешним воздействиям на протяжении нескольких десятилетий, причем решаюшие процессы их созревания происходят еще во время внутриутробного развития. Болсе того, в отличие от мужских гамет, селекция генетически неполноценных гамет у женшин в значительной стелени происходит уже после оплодотворения, а лодавляющее большинство (болсе 90\%) зародышей с хромосомными и генными мутациями отмирает до или во время имплантации [9] - следовательно, основные усили по профилактике наследственной и врожденной патологии, в том числе и индуцированной неблагоприятными факторами внемней среды, должны быть направлены именно на женский организм. Естествелно, это не означает игнорирования влияІгия зкзогенных и генетических факторов на репродуктивное здоровье мужчин, однако благодаря естественным биологическим особенностям созревалия и селекции мужских гамет, а также разработкам новых вспомогательных репродуктивных технологий, профилактика нарушелий репродукции у мужчин в значительной мере упрошается.

\section{Генетические основы профилактики наследственных и врожденных болезней}

Согласно классическим представлениям медицинской генетики различают несколько последовательных уровней профилактики $[3,6]$ :

- Переичная профилактика налравлена на предупреждение рождения больного ребенка. Она включает комглекс мероприятий и рекомендаций, связанных с планированием деторожделия (преколцепционная профилактика, медико-генетицеское консультирование, генетическая карта репродуктивного здоровья (см. ниже).

- вторичная профилактика включает в себя весь комплекс скринируюших программ, инвазивных и неинвазивных методов исследования, дополненных специатьными лабораторными анализами плодного материала, шитогенгтическими, молехулярными и биохимическими методами исслелования с целью предулреждения рождения детей с тяжелыми хромосомными, генными и врожденными пороками развития. Следовательно, по сути, вторичная профилактика охватывает всю пренатальную диагностику,

- И наконец, трегий уровень (mретичная профилактика) касается, в действительности, различных подходов и методов коррекции прояв.'ений уже состоявшихся патологических процессов (генотипов) и включает различные варианты нормокопирования (диета лишенная фенилаланина для предупреждения поражений мозга у больных фенилкетонурией, лечение соответствуюшцим ферментными препаратами бользых диабетом и наследственными болезнями наколления и др.).

Важная роль в профилактике наслсдственной и врожденной патологии, в сохранении здоровья и репродуктивной функции принадтежит предиктивной (предсказательной) медицине [10, 11]. Она представляет собой одно из направлений молекулярной медицины, основанное на результатах и методах расшифровки генома человека, которые позволяют выявлять людей с 
повышенной чувствительностью к тому или июому заболеванию еще в досимптоматический период, адекватно интерлретировать полученные результаты и разрабатывать на основании полученных данных эффективные схемы индивидуальной профилактики и лечсния. Основная цель предиктивной медицины на современном этапе - научить человека жить в гармонии со своими генами [12].

Известно, что практически все гены человека имеют в своей структуре молекулярные отличия (полиморфизмы), приводяшие к синтезу белков с несколько измененными структурными и функциокальными характеристиками. Тестирование функциональных полиморфизмов различных геюов человека, составляющих генную сеть того или иного мультифакторного заболевания формирует молекулярную основу предиктинной медицины. Каждый человек генетически неповторим и, соответственно, для каждого человека характерен свой уникальный биохимический портрет. Именно его особенности предопределяют врожденную предрасположенность человека к тем или иным заболеваниям. Тестируя полиморфизмы генов, выясняя сильные или слабые звенья своего генома, мы можем узнать какая патология и с какой вероятностью ожидает каждого из нас в будущем. Важно, однако, подчеркнуть, что генетическое тестирование дает возможность только выявить имеюшиеся в геноме тенденции к развитию будущих болезней, повышенную чувствительность человека к тем или иным заболеваниям, но не ставит окончательный диатноз. Тем не менее, этой информации достаточно, чтобы, исходя из современного врачебного опыта, наметить пути профилактики многих тяжельх мультифакториальных заболеваний, в том числе и заболеваний, связанных с нарушениями репродуктивной функции и приводящих к нарушениям развития плода.

\section{Гены предрасположенности}

Под генами предрасположенности в предиктивной медицине понимают мутантные гены (аллели), совместимые с анте- и постнатальным развитием человека, но приводящие в неблагоприятных условиях к разлииным заболеваниям [10]. Естественно, что дтя каждого заболевания характерен свой набор таких аллелей, своя «генная сеть» [12]. Вместе с тем, уже сегодня можно выделить несколько достаточно «универсальных» групп генов предрасположенности, участвующих в генезе или провоцируюших развитие многих тяжелых заболеваний. Таковыми являются гены системы детоксикации (метаболизма) (1); генырецепторы (2); гены-«триггсры» (3), продукты которых играют роль метаболических шунтов сразу в нескольких ключевых биохимических реакшиях (налример, ферментт дигидрофолатредуктаза, играет важную роль в лроцессах синтеза нуклеотидов и аминокислот).

Наиболее полно в настоящее время изучены гены системы детоксикации. Исследование полиморфизмов этих геюов и их ассоциаций с различными заболеваниями были начаты в налией лаборатории еще в 1995 году. Первым заболеванием, для которого была установлена неслучайная ассоциация лолиморфизмов этих генов, точнее генов 2-й фазы детоксикации (гены глютатион-трансферазы М- и N-ацетилтрансферазы) был эңдометриоз [13]. Дальнейшие исследования доказали, что функционально нелолноцен ные варианты генов метаболизма играют важную роль в цатогенезе юривычной невынашинаемости [14], плацентарной недостаточности, аденомиоза и даже гестозов [15]. Особенно убедительные данные в отношении полиморфных вариантов этих генов были получены и ция такого частого заболевания детского возраста как атопическая бронхиальная астма [16]. Тестирование полиморфизмов этих генов в семьях высокого риска позволяет с высокой вероятностью провести досимлтоматическую диагностику бронхиальной астмы и своевременно начать ее профилактику.

Анализ полученных данных и обобщенный опыт работы лаборатории пренатальной циагностики НИИ АГ им. Д.О. Отта РАМН позволит сформулировать концепцию профилактики заболеваний, нарушающих репролуктивную функцию женщин (эндометриоз, аденомиоз), нередко осложняющих беременность (привычное невынашивание, хроническая пілацентарная недостаточность, угрожающий ранний выкидыш, гестозы), приводящих к тяжелым нарушениям внутриутробного развития плода (хромосомные болезни, ДЗНТ), либо реализующихся в виде тяжелых генных болезней в постнатальном иериоде. Практическим завершением этой концелции явилась разработка «генетической карты репродуктивного здоровья» $[4,12]$, суммирующей результаты комплсксного молекулярного и цитогенетического обследования супружеских пар, планируюццих ребенка или самих женщин на ранних сроках беременности. Анализ кариотипов обоих супругов, тестирование гетерозиготного носительства наиболее частых мутаций, приводяших к тяжелым наследствен- 
ным заболеваниям (муковисцидоз, гемофилия, миодистрофия Дюшенна, фенилкетонурия и ар.), дополненный результатами исследования наследственной предрасположенности, должен, по нашему убеждению, способствовать повышению уровня репродуктивного здоровья и профилактике тяжелых врожденных и наслелственных болезней у плода.

\section{Экологические аспекты предиктивной медицины}

В целом неблагоприятная экологическая обстановка во многих регионах страны, неудовлетворительное питание, низкос качество питьевой воды, загрязнение атмосферы являются тем неблагоприятным фоном, на котором отмечается снижение качество жизни, нарушение репродуктивного здоровья и рост антенатальньх потерь и постнатальной патологии [4]. Все эти демографические показатели полугены при анализе популяционных выборок населения различных региозов страны. Однако они не учитынают гетерогенность генетитеского состава изученных групп населения [17]. Такие исследования до настояшего времени гроводятся без учета уникальных этнических и индивидуальных особенностей генома, во многом определяюших популяционные и индивидуальныс различия чувствительности к действию неблагоприятных факторов внешней среды. Между тем, опыт предиктивıой медицины убедительно свидетельствует о том, что индивидуальная чувствительность может варьировать в очень широких пределах. Как показывают исследования по фармакогенетике, олин и тот же лекарственный препарат в одной и той же дозировке может обладать лечебным эффектом у олних пациентов, быть вполне приголным для лечения у других и при этом оказывать выраженный токсический эффект у третьих. Такие колебания нормы реакции, как сейчас известно, определяются многими факторами, но в первую очередь зависят от скорости метаболизма препарата и времени его выведения из организма. Тестирование соответствующих генов метаболизма позволяет заранее выявить людей повышенной и пониженной чувствительности не только к определенным лекарствам, но и к различным поврежлающим факторам внсшней среды, в том числе, к промышленным загрязнениям, сельскохозяйственным ядам и другим экстремальным для человека экологическим факторам [18].

Широкое внедрение генетического тестирования в область профилактичсской медицины неизбежно. Однако уже сегодня оно порождает ряд серьезных проблем. Прежде всего, проведение популяционных исследований по наследсгвенной предрасположенности требует внедрсния новых технологий, позволяюших проводить широкомасштабные генетические анализы. В настоящее время для 'тих целей создаются, а в ряде случаев уже созданы специатьные биочипы, значительно упрощаюшие сложную и трудоемкую процедуру генетического тестирования, Специальный биочип для тестирования 6-ти полиморфизмов 4-х основных генов детоксикации уже разработан в наших совместиых исследованиях с Центром биологических микрочипов Института молекулярной биологии им. В.А. Энгельгардта РАН [19]. Использование таких биочигов и внедрение новых технологий генетического тестирования позволяет надеяться, что уже в ближайшее время проведение скрининговых исследований полиморфизмов многих генов предрасположенности станет вполне реальным.

Однако такое тестирование может оказаться бесполезным, а возможно даже врелным, если оно не будет подкреллено серьезными медицинскими гарантиями, если оно не получит подцержки со стороны руководителей здравоохранения и правительства, если оно не будет закреплено соответствуюшими правовыми и законодательными документами. Правовые и юридические вопросы предиктивной медицины и, прежде всего, тестирования генов предрасположенности в настоящее время активно прорабатываются различными международными комитетами и комиссиями. Они уже стали предметом оживленных обсуждений и в отечественной литературе [20].

В этой связи уместно напомнить о документе, недавно представ: енном в парламент Великобритании группой ученых и специалистов в области генетики человека. Документ под названием «Наша наследственность - наше будуıщее» рекомендует в законодательном порядке переориентировать все здравоохранение страны на основе последних лостижений генетики и программы «Геном человека», успешно завершенной в 2003 году. Предполагается создание спениальных центров подготовки консультантов по медгенетике, предоставляющих адекватную информацию по результатам генетического тестирования, обучение медгенетике всего медперсонала, всесторонняя, прежде всего, финансовая поддержка исследований по фармакогенетике, генной терапии и предиктивной медицине. Отрадно, что и в Россиинаууровне правительства и олдентеред

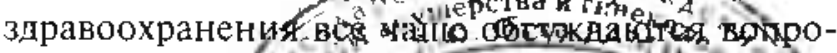


сы медицины здорового человека. Естественно, что ее методическую и кониептуальную основу должна составить медицина профилактическая, центральное место в которой будет по праву приналлежать генетическому тестированию наследственной предрасположснности. Индивилуальный подход и профилактическая направленность предиктивной медицины очевидны [10, 17, 18].

\section{Заключение}

Таким образом, экологической генетике человека принадлежит важная, а во многих аспектах и решающая роль в сохранснии репродуктивного здоровья, профилактике наследственной патологии и врожденных пороков развития у плода и новорожденного. Особенно важное место в решснии этой сложной и многограннюй проблемы принадлежит охране репродуктивной функции женщины-матери, повреждающее действие внешней среды на гаметы которой в силу биологических особенностей оогенеза, растягивается на несколько поколений. Большую роль в сохранении репродуктивного здоровья, равно как и в профилактике наследственных болезней, врожденных пороков и досимптоматической диагностике наиболее частых заболеваний постнатального периода играет предиктивная медицина. Методическую основу последней составляет тестирование генов «лредрасположенности», а в оценке индивидуальной чувствительности к неблагоприятным экологическим факторам - тестирование полиморфизмов в генах системы детоксикации. Сушествующие и успешно разрабатываемые в настояшее время новые методы ДНК-анализа, прежде всего метод биочипов, позволяют уже сеголня сделать такие исследования массовыми, то есть перевести тестирование на уровень скрининга. Требуются, однако, дальнейшие исследования для оценки предиктивной ценности таких генетических тестов. Еще более серьезным препятствием к их широкому внедрению является отсутствие соответствующей юридической и правовой базы, равно как отсутствие готовности современной медицины к переориентации в сторону здорового человека.

Согласно прогнозам авторитетных специалистов, золотой вск предиктивной медицины настулит только через десять лет, когда будет накоплено достаточно информации о генных сетях разных заболеваний и о реальной предиктивной ценности различных генетических тестов.
Проведение обширных эпидемиологических исследований по тестированию генов «предрасположенности" с последуюшим цлительным на6нюдением за людьми с различными генотинами по генам детоксикации или по другим генам «Предрасположенности» могло бы иметь решающее значение дјя оценки прогностической ценности таких тестов. Именно такие исследования в 2003 году были начаты в Великобритании, где уже создается биобанк образцов ДНК 500000 британщев. Эти образщы тестируются на разные генетические полиморфизмы, а сами доноры ДНК будут находиться под наблюдением врачей в течение 10-20 лет. Предполагается, результатом таких исследований станут более объектинные результаты предиктивной цеиности соответствуюших генетических тестов.

Нет сомнений в том, что уже сегодня, работая в области предиктивной медицины, скрупулезно сопоставляя данные генетического анализа с результатами лабораторных и клинических исследований, можно не только существенно укрепить научные основы этого многообещающего научного направления постгеномной эры, но и принести ощутимую практи:ескую пользу в деле профилактики многих тяжелых недугов. Весьма миогообешаюици представляется широкое внедрелие предиктивной медицины и в область экологической генетики человека. Массовые генетические тестирования позволят болсе точно оценить поврсждающее действие на организм человека неблагоприятных факторов внешней среды в зависимости от этнических и индивидуальных особенностей генома. Такие исследования, равно как повсеместное внедрение в работу родовспомогательных учреждений «Генетической карты репродуктивного здоровья", будут способствовать сохранению репродуктивного здоровья населения России и повысят эффективность профилактики наследственных и врожденных заболеваний.

\section{Литература}

1. Покровский В.И., Тутельян В.А. Научные основы охраны здоровья детей. / Постановление XIV (77) Сессии РАМН. 2004. 9-11 дехабря. - C. 1-7.

2. Экологическая доктрина Российской Федерации. М 2003. - C. $1-30$

3. Айламазян Э.К.// Акуш.и иин. - 2003

4. Баранов В.С., Романенко О.П., Симаходский А.С., Алферова Н.К., Мусийчук Ю.И. Частота, диагностика и профилактика наследственных и врожденных пороков развития в Санкт. Петербурге. СП6.: Медицинская пресса, 2004. - 175 с

5. Бочков Н.П. Экологическая генетика человека. // Экол. генет / Ecol. genet. - 2003, T. 0, C. 16-21.

6. Бочков Н.Л. Клиническая генетика. М.: ГЭОТАР-МЕД, 2001. $-447 \mathrm{c}$. 
7. Кнорре А.Г. Основы эмбриологии человека. Л.: Медицина, 1967. - 347 с.

8. Golubovsky M. D. Manton K. Oocytes physically and genetically link three generations: genetic/demographic implications // Environment and perinatal medicine. SPb, $2003-P .354-356$

9. Дьбан А.П., Баранов В.С. Цитогенетика развития млекопитающих. М.: Наука, 1978. - 216 С

10. Баранов 8.C., Баранова Е.В., Ивашенко Т.Э. Асеев М. В. Геном человека и гены "предрасположенности". Введение в предиктивнуюмедицину. СПб.: Интермедика, $2000-271 \mathrm{c}$

11. Баранов В.С., Айламазян Э.К. Молекулярная медицина новое направление в диагностике, профилактике и в ле. чении наследственных и мультифакториальных болезней. // Мед. акад. ж. - 2001. - Т. 3. - С. 33-43.

12. Баранов В.С., Баранова E.8., Ивашенко Т.Э. Научные основы предиктивной медицины // В кн. Молекулярно-биологические технологии в медицинской практике. Новосибирск: Изд. Альфа-Виста, 2003, Вып. 4. - С. 3-19.

13. Usед Н Ю., Ивашенко Т.Э., Крамареяа Н.Л. и др Ассоциация аллельных вариантов некоторых генов детоксикации с результатами лечения больных эндомет риозом. // Мед. генет. - 2002. - T. 1, № 5. C 242-245.

14. Беспалова О.Н., Аржанова О.Н., Ивашенко Т.Э., Асеев М.В., Айламазян Э.К., Баранов В.С. Генетические факторы предрасположенности к привычному невынашиванию беременности ранних сроков // Ж. акуш. жен. болезн, 2001. - T. ᄂ, вып. ? - С. 8-13.

15. Мозговая E. B., Малышева О.В., Иеаценко Т. Э., Баранов B.C. Полиморфизм генов, участвующих в регуляции фунхции эндотелия и его сөязь в развитии гестоза. // Мед. генет. - 2003. - T. 2, № 7. - C. 324-330

16 Ivaschenko T.E., Sideleva O.G., Baranov V.5. Glutathione-S-transferase micro and theta gene polymorphisms as new risk factors of atopic bronchial asthma $/ / \mathrm{J}$. Mol. Med. - 2002. - vol 80(1) - P. 39-43.

17. Гиятер Е.К. Медицинская генетика. М.: Медицина, 2003. - 448 с.

18. Пузырея В.П. Геномная медицина - настоящее и будущее // В кн. Молекулярно-биологические технологии в медицинской практике. Новосибирск: Изд. Альфа-Виста, 2003, Вып. 3- С. 3-26.
19. Глотов А.С., Нващенко Т. Э., Баранов В.С., Наседкина T.В. Создание биочипа для фармакогенетических исследований. // III сьезд ВОГИС. Генетика в XXI веке: современное состояние и перспективы развития. Москва, 6-12 июня 2004 года. Тез. докл. - С. 8.

20. Ижевская В.Л. Иванов В.И. Геномика и медицина: этические проблемы и подходы К их решению. // В кн Вөедение в молекулярную медицину / Ред. М.А. Пальцев. М. Медицина, 2004. - C. 11-34.

\section{ECOLOGICAL GENETICS, REPRODUCTIVE HEALTH AND PREDICTIVE MEDICINE}

\section{Baranov V.S.}

Summary: Ecological genetics plays a major role in protecting reproductive health and prevention of inherited and inborn disorders. Protection of reproductive health in women poses special problems as because of long period of oogenesis damaging of female gametes is feasible during several successive generations. Recent achievements in predictive (preventive) medicine render opportunities for presymptomatic diagnostics and efficient prevention of inherited and inborn disorders as well as severe and common diseases in postnatal life. Testing of genetic polymorphisms creates solid genetic background in predictive medicine. Thorough studies are needed to evaluate predictive value of already existing genetic tests. Necessities for solid legislative background and comprehensible medical evaluation of genetic tesis reșults are also quite urgent tasks of current medicine. Widespread population genetic testing with subsequent relevant interpretation of the results might pave the way for more objective evaluation of unfavorable action of ecological factors in humans. These studics in conjunction with already elaborated Genetic Chart of Reproductive Health might help a lot in protecting of reproductive health as well as in prevention of inherited and inborn disorders.

- Key words: ecological genetics; reproductive health; predictive medicine; genetic testing; predisposition genes 